\title{
RELATIONSHIPS BETWEEN PHENOMENA OF PARADOXICAL SLEEP AND THEIR COUNTERPARTS IN WAKEFULNESS
}

\author{
Adrian R. MORRISON \\ Laboratories of Anatomy, School of Veterinary Medicine and Institute \\ of Neurological Sciences, University of Pennsylvania \\ Philadelphia, Pennsylvania, USA
}

Abstract. Our studies suggest that paradoxical sleep is a state in which the brainstem is in a functional mode normally associated with presentations of novel stimuli. Furthermore, the combination of atonia and an internal state of activation indicates sustained activity of a brainstem mechanism designed to dampen responses to sudden, novel stimuli in wakefulness lest the animal over react and run blindly into danger prior to stimulus analysis. This conclusion stems from two sets of data. Studies of large-amplitude waves, which characteristically occur spontaneously just prior to and during paradoxical sleep, have demonstrated that the waves are signs of alerting. These waves, termed ponto-geniculooccipital (PGO) spikes, can be induced during both slow wave and paradoxical sleep by external stimuli at a threshold below actual arousal. Whenever cats are confronted with novel stimuli during wakefulness, eye movement potentials, which are recorded from the same sites as PGO spikes but differ from them in several characteristics, assume all the characteristics of PGO spikes. These observations indicate that the central nervous system during paradoxical sleep is in a "peculiar" state of activation which is not behaviorally expressed. Other experiments have focused on the muscle atonia of paradoxical sleep. Small, bilateral dorsolateral pontine tegmental lesions create the dramatic phenomenon of paradoxical sleep without atonia which is characterized as follows: After slow wave sleep, when paradoxical sleep with muscle atonia would 
normally appear, cats raise their heads, make body righting movements, exhibit alternating movements of the limbs, and even attempt to stand. Throughout an episode, which shows all other aspects of paradoxical sleep, including unresponsiveness to visual stimuli, cats act as if they are being startled, searching and sometimes attacking an object. In wakefulness they show minor cerebellar signs. Presumably the lesions disrupt both the pontine excitation of the medullary inhibitory area and the inhibition of a brainstem system for mobilizing activity normally in force during paradoxical sleep. Studies of the same cats during wakefulness have shown that there in an increase in exploratory locomotor activity of 23 to $127 \%$ as measured in an open-field test. The existence of parallel effects on motor control in wakefulness and paradoxical sleep produced by pontine lesions suggests that the atonia of paradoxical sleep is a reflection of excessive activity of a brainstem response dampening mechanism which operates more subtly during wakefulness to produce appropriately modulated responses to various unexpected stimuli.

Until 1949 the view that sleep was a passive process resulting from the withdrawal of sensory input via the long sensory pathways necessary for wakefulness dominated thinking about the relationships of sleep to
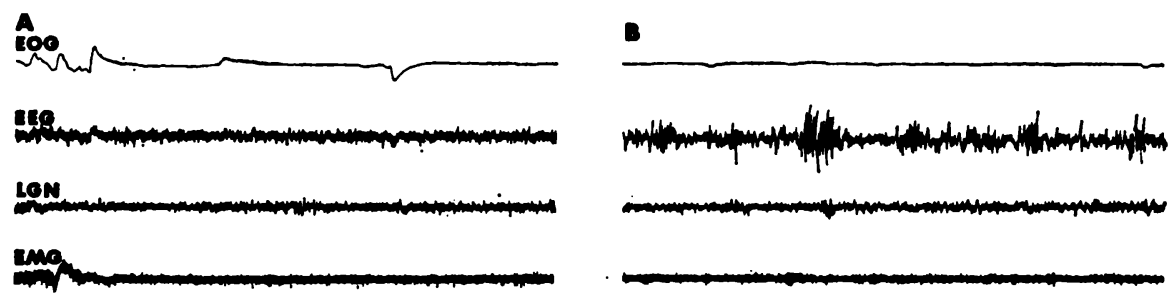

c
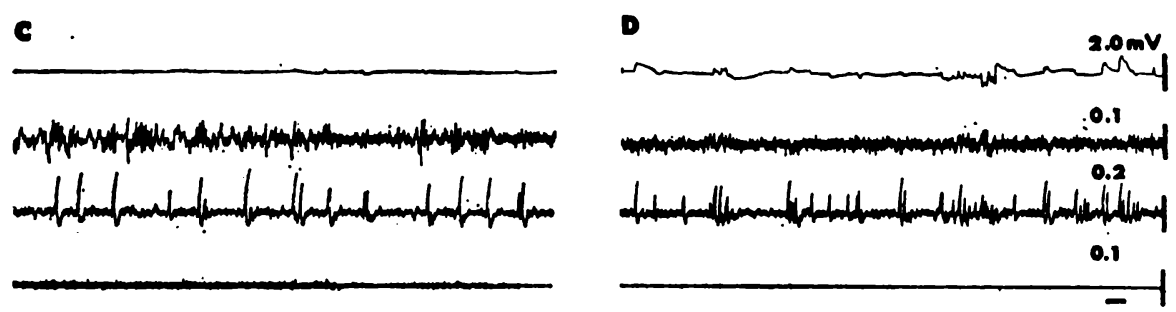

Fig. 1. Characteristics of the behavioral states of (A) quiet wakefulness; (B) slow wave sleep; (C) transition from slow wave sleep to paradoxical sleep; (D) paradoxical sleep. EOG, eye movements recorded on the electro-oculogram; EEG, electroencephalogram; LGN, recording of PGO spikes in the lateral geniculate body in C and $\mathrm{D}$, but eye movement potentials practically absent in A; EMG, electromyographic activity of the dorsal cervical muscles which disappears at the end of $C$ and in $D$.

Time calibration $=1 \mathrm{~s}$. From Morrison (33). 
wakefulness (42). The landmark discovery of Moruzzi and Magoun (43), however, showed that the brainstem reticular formation was involved in EEG activation. This work presaged discoveries of greater complexities in the organization of sleep and wakefulness, which demonstrated that the process of falling asleep and remaining asleep involved active mechanisms (41). The primary stimulus for the modern era of sleep research (since 1953) was, of course, the "unusual" nature of paradoxical sleep, first detected by Aserinsky and Kleitman (1). That is, instead of the high-amplitude, slow wave activity recorded on the electroencephalogram (EEG), which had until then been regarded as characteristic of sleep, low-amplitude, high-frequency activity quite similar to that of wakefulness characterized the EEG of paradoxical sleep (Fig. 1). Paradoxical sleep also differs from wakefulness in a number of ways of course. In cats, which will be the subject of this paper and which exhibit a representative mammalian sleep pattern, responsiveness is reduced; the pupils are miotic; the nictitating membranes are relaxed; neuronal firing is more burst-like; and the skeletal musculature is atonic although phasic twitches of the distal limb musculature, facial musculature and extraocular muscles occur (22). The latter are responsible for the well-known rapid eye movements of this sleep stage. Such observations are made on cats implanted with chronic electrodes and sleeping in a lighted chamber (33).

In spite of these dramatic differences, some similarities exist between paradoxical sleep and alert wakefulness in particular in addition to the EEG pattern. In both states brain temperature is higher than in slow wave sleep (45), and theta rhythm is present in the hippocampus (22). Before proceeding, a significant point must be made regarding comparisons between these states. In comparing sleep and wakefulness sleep researchers, who have done so much to emphasize the importance of studying behavioral state changes as they relate to sleep, have, ironically, compared the various phenomena measured during slow wave and paradoxical sleep to those of wakefulness as if the latter were a homogeneous state. Indeed, the qualifiers "alert" and "quiet" have been indiscriminately applied to the state of wakefulness in reporting on differences in neuronal firing, reflexes and other aspects of the sleep states and wakefulness. For obvious technical reasons workers have tended to study quiescent animals, which naturally limits the range of the wakeful state subdivisions available for analysis.

Yet, it has become increasingly clear to us that much of paradoxical sleep, at least, becomes understandable if one examines its various aspects from the point of view that the central nervous system is in a state which one would call a state of "orientation" were the organism interact- 
ing with its environment. More specifically, our experiments have led us to conclude that paradoxical sleep resembles a state in which the brainstem is in a functional mode normally associated with presentations of novel stimuli. Furthermore, the combination of atonia and an internal

A

AUD

506

EEG

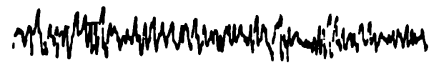

CORTEX

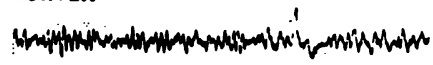

LGN

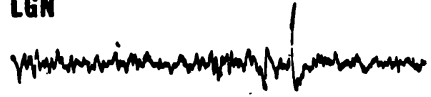

SS

darkness a

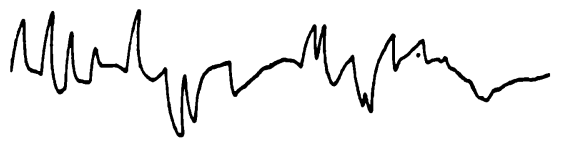

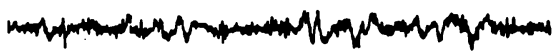

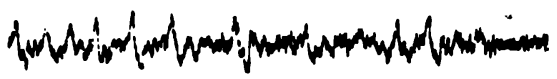

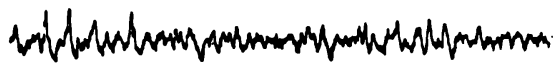
awake light

C

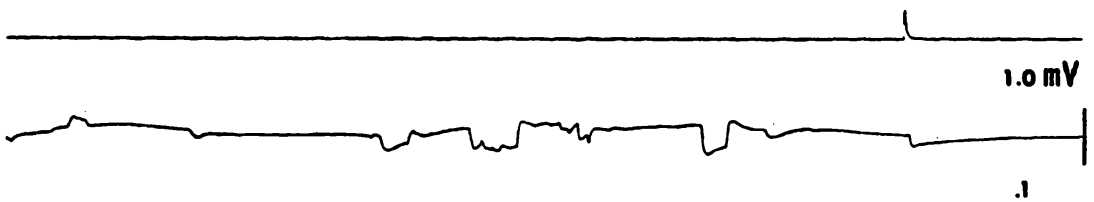

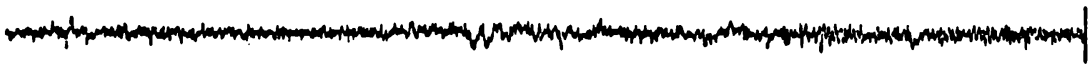

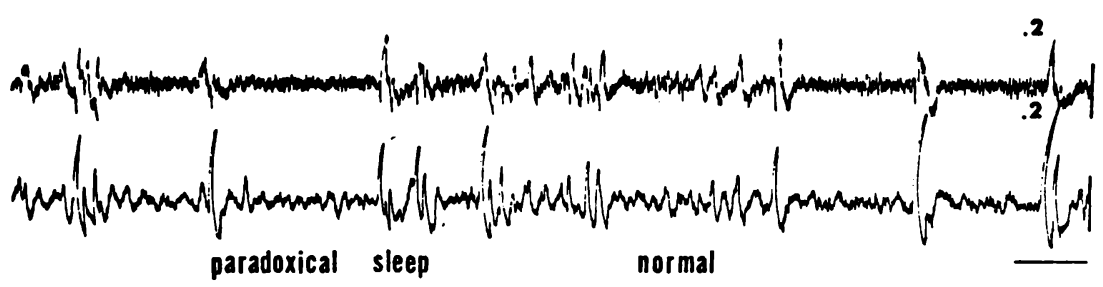

Fig. 2. (A) Normal cat in slow wave sleep (ss) exhibiting a sound-induced PGO spike in lateral geniculate body and visual cortex while in a darkened recording chamber. Compare amplitude of the induced spike with those of spikes in B and C. A transient EEG change also occurred, but the cat then continued in slow wave sleep. AUD, auditory stimulus marker; CORTEX, visual cortex. (B) Same animal during wakefulness in the light illustrating spontaneous eye movements accompanied by LGN and cortical eye movement potentials. (C) Normal cat in paradoxical sleep illustrates spontaneous PGO spikes and a sound-induced PGO spike (AUD marker) recorded from the LGN and visual cortex. Time calibration $=1 \mathrm{~s}$. From Bowker and Morrison (5). 
state of activation can be viewed as sustained activity of a brainstem mechanism designed to dampen responses to sudden, novel stimuli in wakefulness lest the animal over react and run blindly into danger prior to stimulus analysis $(33,36)$.

This concept began to evolve with our observation $(5,35)$ that normal1y spontaneous events of paradoxical sleep, ponto-geniculo-occipital (PGO) spikes, could also be elicited by environmental stimuli, not only during paradoxical sleep, but also during slow wave sleep (Fig. 2). PGO spikes are large-amplitude waves recorded by means of macroelectrodes in the pontine tegmentum, lateral geniculate body and occipital cortices 10-30 s prior to and during paradoxical sleep (Fig. 1, C and D) (23). They were first recorded in the pons by Jouvet and Michel (24) and then in the lateral geniculate body by Mikiten et al. (31). Continued work by others demonstrated (1) that the pathways responsible for the waves course through the reticular formation to both the lateral geniculate body and visual cortices in parallel $(3,8,26,27)$ but not to the sensory motor cortex (7) and (2) that activity of the serotonergic raphe nuclei seemed responsible for confining the waves to paradoxical sleep and the immediately preceding transition period (56). Morrison and Pompeiano (39) showed that there are two types of PGO spikes - one which occurs singly in the transition period and throughout an episode (Type I) and the other (Type II) which appears in clusters associated with rapid eye movement bursts. Bilateral vestibular nuclear lesions eliminated both rapid eye movement bursts and Type II clusters but did not affect the Type I spikes. It therefore appeares that the Type II spikes represent activity in the vestibulo-oculomotor system activated internally during paradoxical sleep since rapid eye movements continue after bilateral vestibular nerve section (48). Type I spikes seem a more fundamental part of the paradoxical sleep state, and it is these individual spikes which are evoked by auditory or tactile stimuli during both slow wave and paradoxical sleep $(5,35)$.

Both natural laboratory sounds and light hair touch were found to evoke waves in the lateral geniculate body during both paradoxical and slow wave sleep. The waves appeared identical in shape to PGO spikes. In order to study this phenomenon in detail pure tone bursts were applied, and recordings were made in both the lateral geniculate body and marginal gyrus within the primary visual area. Several revealing observations were made which led us to conclude that PGO spikes are signs of activation of the reticular alerting network: (1) The waves could be evoked during slow wave sleep at a threshold lower than that which would elicit generalized EEG activation or behavioral evidence of arousal. (2) The latency of the waves was. usually 20 to $40 \mathrm{~ms}$; whereas that 
of the evoked response in the auditory cortex was $10 \mathrm{~ms}$ (3) If stimuli were presented at frequent intervals in slow wave sleep, e.g. every $5 \mathrm{~ms}$, the waves diminished in amplitude and then disappeared after a few repetitions. During paradoxical sleep, on the other hand, waves could be evoked at the same latency as those in slow wave sleep at least $60 \%$ of the time. (4) Cats with cerebellar cortical lesions exh'́bit spontaneous flexor or extensor jerks of the forelimbs depending upon the location of the lesion during the transition period between slow wave and paradoxical sleep, and these jerks occur synchronously with PGO spikes until muscle atonia ensues (34). Auditory stimuli elicited the same jerks in addition to PGO spikes (35).

The evidence indicated that the evoked waves were the result of nonspecific activation. The fact that the evoked waves and spontaneous PGO spikes have at least three properties in common argues for the view that they are both merely a sign of reticular activation: (i) the waveforms have an identical appearance, (ii) they both can occur in paradoxical sleep, and (iii) they are both associated with limb jerks in cerebellar-lesioned animals. The last is easily explained. PGO-associated waves occur spontaneously in the cerebellar cortex during the transition to and during paradoxical sleep (46). Because the deep cerebellar nuclei are excited by collaterals of fibers extending to the cerebellar cortex, they would be affected by this brainstem-generated input (19). An auditory stimulus directly excites both deep cerebellar nuclear neurons and Purkinje cells (40). If the overlying inhibitory Purkinje neurons (19) are removed, any input to the deep cerebellar nucleus normally modulated by the damaged cortex would have an exaggerated effect on cells to which the deep cerebellar nuclei project. Thus, damage to the midline vermal region results in extensor jerks because such neurons as those of the lateral vestibular nucleus, which primarily excite extensor motor neurons (28), are unchecked; and a paravermal lesion leads to flexor jerks because the red nucleus, which facilitates flexor motor neuronal activity, is powerfully driven by the released interpositus neurons (63). During wakefulness a sudden external stimulus will incite a flexion movement or an exaggerated extensor posture depending upon whether the lesion is in the paravermal or vermal cortex $(35,63)$.

These relationships led to the experiments which were the next step in the evolution of the hypothesis that paradoxical sleep can be viewed as a period during which the central nervous system acts as if there were a continual influx of unexpected, or novel, stimuli. During wakefulness potentials occur in the same locations as PGO spikes (Fig. 2B); and because of their association with eye movements, they have been named eye movement potentials (14). Brooks and Gershon (10), however, 
have recognized their essential similarity to PGO spikes and have proposed the terms $P G_{W}$ and $P G O_{R E M}$ in recognition of this. The fact that both are eliminated during reversible cooling of the dorsolateral pontine tegmentum supports this idea (27). At the other extreme, Sakai and Cespuglio (52) have stated that there are two classes of waves in paradoxical sleep determined on the basis of latency of appearance in the lateral geniculate body following a wave in the abducens nucleus. Those with a longer latency were termed eye movement potentials of paradoxical sleep because of similarities to those of wakefulness. All workers, however, consider that there are certain differences between the two waves, the most significant probably being the effects of levels of illumination on the amplitudes of the waves. Cortical PGO spikes are unaffected by light, but amplitudes of eye movement potentials are greatly diminished in darkness $(10,20)$.

Primed by our observations that alerting stimuli could elicit waves which seemed in every respect to be PGO spikes, we postulated that the critical factor responsible for the amplitudes of eye movement potentials was the animal's state of alertness, not level of illumination (6). Even in total darkness a tone burst increased the amplitude of eye movement potentials to the same levels of those of PGO spikes for a few seconds

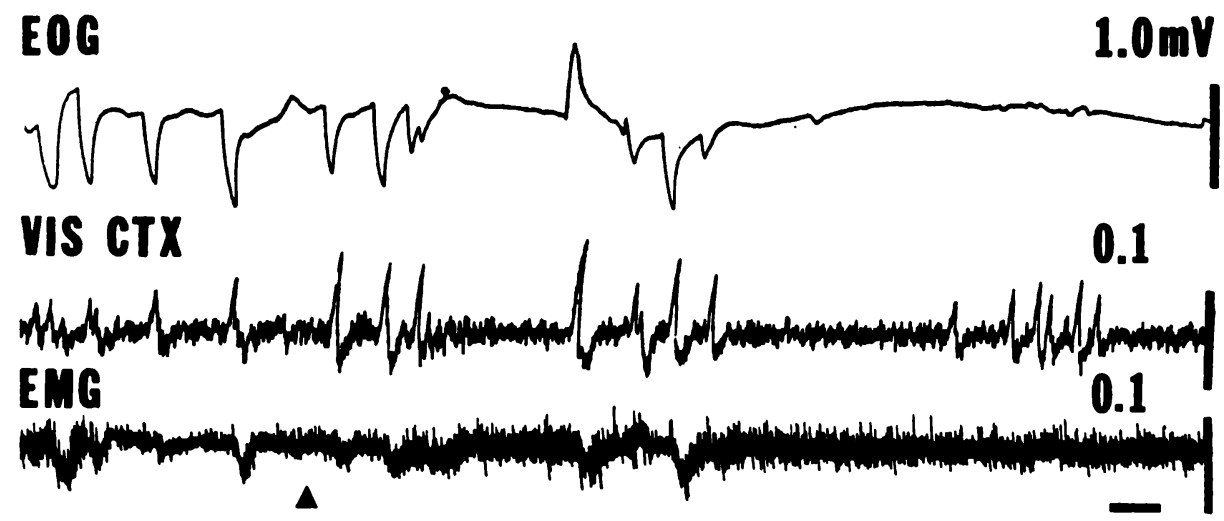

Fig. 3. Recording of a cat during wakefulness while in darkness. When the cat was alerted by a noise (triangle), the EMP increased in amplitude, then became attenuated as quiet wakefulness ensued. VIS CTX, visual cortex; time calibration = 1 s. From Bowker and Morrison (5). Vigilance: An important determinant of cortical eye movement potentials. From Sleep Res. $5: 37$.

(Fig. 3). The determining factor seems to be the novelty of the stimulus, because the odor of fish would also increase for only a brief period the eye movement potential amplitudes of a food-deprived cat housed in darkness. Furthermore, Bowker (4) has demonstrated that once cats have 
learned the significance of a visual stimulus, eye movement potentials greatly diminish in amplitude even though eye movements remain. The amplitudes return to their original level if a novel stimulus is interjected.

The effect of novel stimuli on the visual system at the cellular level is probably to enhance transmission at a time when this would be quite useful, in the presence of novel stimuli. Indeed, there is considerable evidence that reticular stimulation acts to disinhibit geniculate and cortical cells, and such stimulation produces a PGO-like geniculate wave (57).

Although similarities among eye movement potentials, PGO spikes evoked in slow wave sleep, and spontaneous and evoked PGO spikes of paradoxical sleep have been stressed thus far in this paper, there is a difference, previously mentioned, between the first two waves and those occurring in paradoxical sleep, which is important to recognize if one is to explain the nature of the paradoxical sleep state. During paradoxical sleep the waves exhibit little tendency toward habituation. Bizzi and Brooks (3) showed that stimulation within the pontine region from which PGO spikes were recorded would elicit PGO spikes within the lateral geniculate during paradoxical sleep with every stimulation, but that stimulation during slow wave sleep would not evoke them at all. Several studies have strongly implicated the serotonin-containing raphé nuclei as modulators of PGO spike appearance. Interference with serotonin metabolism by administration of reserpine or para-chlorphenylalanine leads to continual occurrence of PGO spikes (23). Indeed, it was the remark that cats under the influence of para-chlorphenylalanine seemed to orient or be startled with appearance of each PGO spike (12) that led us to formulate the hypothesis that PGO spikes were a sign of activation of the startle reflex network $(5,35)$ [later generalized to alerting (6)]. Single-unit recordings of dorsal raphé neurons have shown that here is a cessation of firing just prior to a PGO spike in the transition period and that the neurons stop firing altogether during an episode of paradoxical sleep $(30,61)$. Finally, in an ingenious sequel to the original Bizzi and Brooks studies $(3,9)$, Simon et al. (56) studied the effects of parasagittal brainstem sections on the "gating" effects of the raphe nuclei on PGO spike appearance. They demonstrated that pontine stimulation lateral to the cut would elicit PGO spikes in the lateral geniculate body during both slow wave sleep and paradoxical sleep but that stimulations on the opposite, intact side still only produced the waves in paradoxical sleep. This study indicates that raphé neuronal activity does probably gate PGO spike occurrence and that the circuitry involved in PGO spike regulation is reasonably precise.

The foregoing leads one to the conclusion that paradoxical sleep is 
a period during which the reticular formation, at the very least, operates as if it were incapable of habituating to novel stimuli. But, of course, the organism itself gives no evidence of interacting with the environment; for except for twitches of various muscles, especially those of the distal limbs and face, paradoxical sleep is characterized by atonia, i.e. muscle paralysis. Descending pathways, stemming presumably from the medullary inhibitory area (29), inhibit the spinal motor neurons postsynaptically to produce the atonia $(15,38)$. It is this muscular paralysis, coupled with a state of apparent EEG activation, which has generated the genuine puzzlement about the nature of this sleep state. Our experiments have led us to the conclusion that the extreme motor inhibition is a natural accompaniment to the activation expressed by an EEG arousal pattern and the continual signs of alerting in the form of PGO spikes. Both the activation and motor inhibition can be viewed as an exaggeration of the mechanism which must operate almost continually, but with varying intensity on the efferent side, to identify new and/or unexpected stimuli in daily life and then to regulate the response.

The alerting response we have studied in the form of PGO spikes during slow wave sleep and high-amplitude eye movement potentials seems to have the characteristics which would make it a component of the orienting reflex (58). A useful accompaniment to exposure to a novel stimulus would be a brief period of hesitation to allow time for analysis of significance of the stimulus provided that the animal is not forced into immediate action as when too close to a predator (50). The inhibitory area of the medullary reticular formation (29) may act in normal life at the most basic level to provide the element of supraspinal control of spinal motor neurons necessary to allow a brief time for stimulus analysis. Rather than the overwhelming inhibition that electrical stimulation induces, the degree of inhibition should be just enough to reduce the reactivity of motor neurons to other influences to prevent movement, not produce collapse of antigravity muscles.

If paradoxical sleep is an exaggeration of this mechanisms, it is probably not the only one. In response to a sudden strong stimulus such as being grasped by a predator, a variety of animals exhibit a seemingly paradoxical response; they "freeze" (59). Variously called animal hypnosis, tonic immobility, or the still reaction, the behavior is characterized by depression of spinal reflexes and hypotonia, as is paradoxical sleep; but the EEG may be either synchronous or asynchronous (11). Significantly, as the novelty of the stimulus wears off in test experiments by human handlers, the probability of inducing tonic immobility diminishes (50). As Ratner has suggested (50) this reaction, occurring when an animal is held by a predator, is really an extreme variant of the 
behavior (freezing) which accompanies encounters with novel or unexpected stimuli throughout the day. Depending upon the nature of the stimulus, an animal will fight or escape at intervening distances.

Furthermore, it is not unlikely that narcolepsy represents a pathological variation on this theme. Narcolepsy is a sleep disorder characterized by sleep-onset paradoxical sleep episodes, rather than the usual sequences of slow wave sleep followed by paradoxical sleep, and episodes of partial or total muscular paralysis known as cataplexy, which may or may not be accompanied by some alteration of consciousness. Germane to this discussion is the fact that intense stimuli incite the attacks, e.g. laughter, anger, excitement, suprise (16), rather than the low-intensity, monotonous stimuli which will induce slow wave sleep (49).

The lower brainstem from which PGO spikes, signs of a highly activated reticular formation, originate (3) is probably the seat of the rather primitive behaviors we have been discussing. In cats transected in the
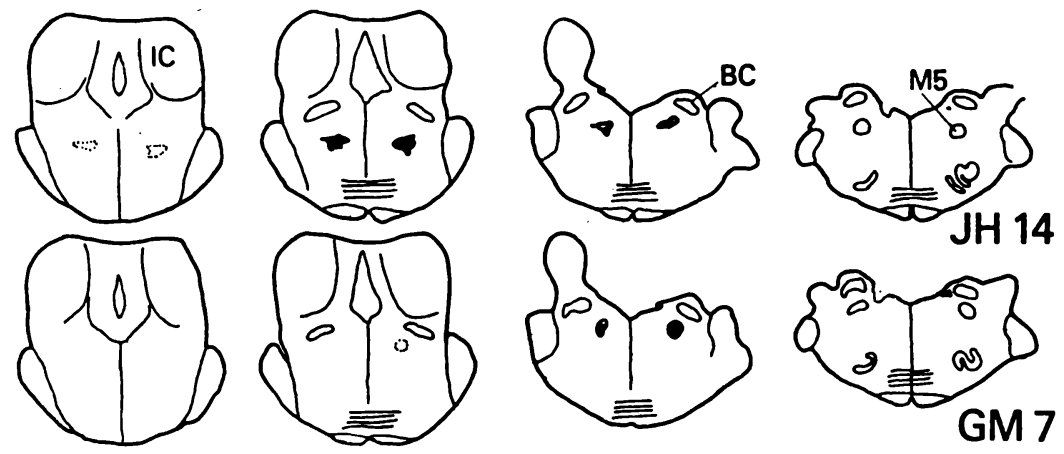

Fig. 4. Lesions which produced paradoxical sleep without atonia. Lesions are denoted by black areas sometimes surrounding areas of cavitation. Dotted circles indicate gliosis. Cross-sections are, from left to right, from stereotaxic levels P1 to P4. Both exhibited raising of the head, body righting, searching, and locomotor movements. JH14 also displayed attack. BC, brachium conjunctivum; IC, inferior colliculus; M5, motor nucleus of the trigeminal nerve.

lower mesencephalon peripheral elements of paradoxical sleep - muscle atonia, twitches and rapid eye movements - will appear $(21,62)$. Local application of the acetylcholine agonist, carbachol, into the pontine tegmentum will induce prolonged bouts of atonia with other elements of paradoxical sleep (60). Raphé lesions will induce abrupt transitions from wakefulness to paradoxical sleep characteristic of narcolepsy $(23,56)$. Small, bilateral pontine lesions (Fig. 4), however, will eliminate the atonia of paradoxical sleep so that cats exhibit hallucinatory-like behavior with PGO spikes $(18,24)$ and possess the other aspects of paradoxical 

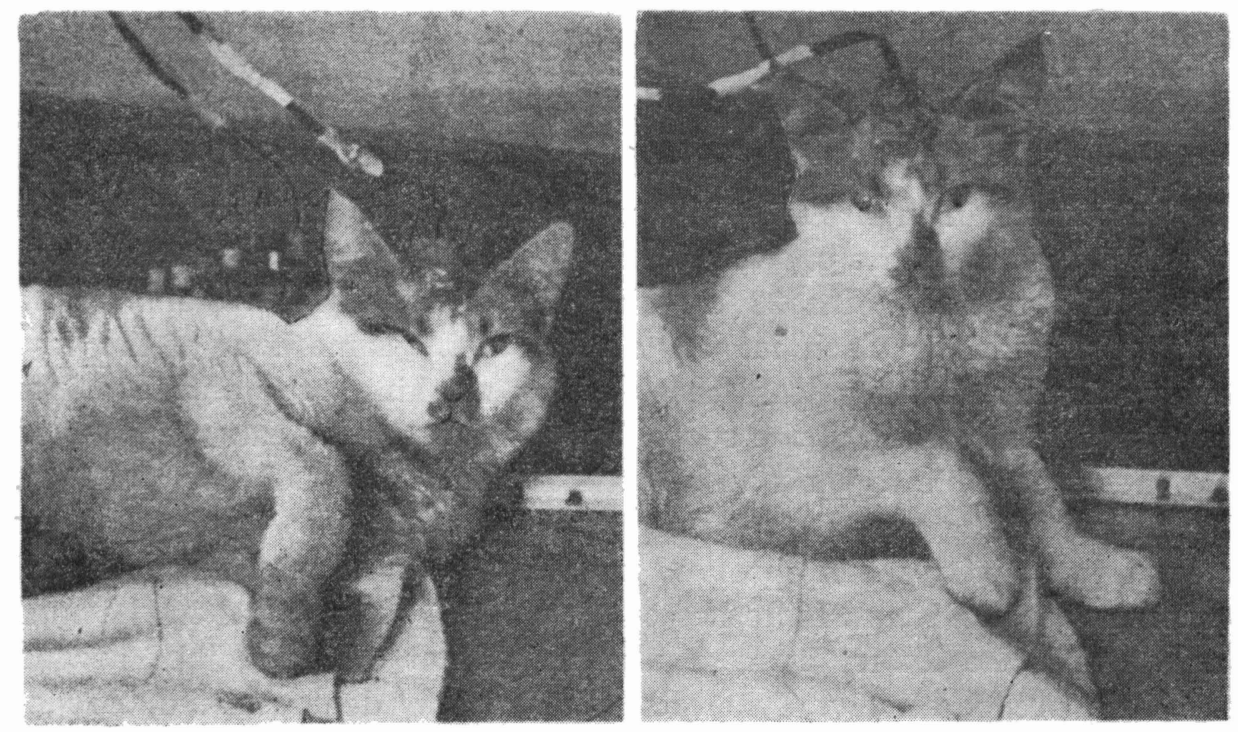

Fig. 5. A cat with bilateral pontine lesions at the initiation (A) of an episode of paradoxical sleep without atonia and fully erect (B) during the same episode. Note the relaxed nicitiating membranes. Frames from a movie taken with floodlamps 1 mo after lesioning. From Henley (18).

sleep which have been measured - activated EEG, rapid eye movements, muscle twitches, miotic pupils and relaxed nictitating membranes, hippocampal theta rhythm, and increased brain temperature (Fig. 5) .(17). During wakefulness such animals show no evidence of generalized hypertonia as in decerebrate regidity so that the lesions do not merely produce an increase in antigravity muscle tone across behavioral states. The behavior exhibited during episodes of paradoxical sleep without atonia consists mainly of orienting and searching with the head and forequarters, attempts at locomotion and, in some cases, actual rage and attack behavior.

Because of the behavior released during paradoxical sleep and the essentially normal muscle tone of the cats during wakefulness, we have postulated that the lesions do more than simply eliminate the normal inhibition of spinal motor neurons $(33,36,37)$. In our view, the lesions interfere, at the very least, with mechanisms normally limiting locomotor behavior during paradoxical sleep. Such a limitation would seem to be an integral part of the motor regulation accompanying novel stimulus presentation.

In pursuing the argument that paradoxical sleep presents us with an exaggeration of this mechanism, we proposed that the release of orienting and exploratory behavior during paradoxical sleep by the pontine 
lesions should be paralleled by some increase in exploratory behavior during wakefulness $(33,37)$. In order to test this hypothesis we studied exploratory behavior before and after bilateral pontine lesions in 9 cats (Fig. 4). The animals were observed during sleep, examined neurologically, observed in their free-ranging behavior and also submitted to open-field tests. For the open-field test each cat was placed into a room marked into squares with $23 \mathrm{~cm}$ sides for 5 one-hour sessions before and after the lesions. Each cat was studied at the same hour of the day, usually 11 a.m. Activity was measured by marking each entrance into a new square on a map of the room. Postoperatively the cats were tested after they were able to walk with minimal ataxia, normally within 2 wk. All cats exhibiting paradoxical sleep without atonia also increased their exploratory activity when observed moving about the laboratory as well as in the open-field test. Increases of 23 to $127 \%$ were noted in the cats. The cat with the lowest increase was an old cat which walked around very little preoperatively. Two cats, which never demonstrated paradoxical sleep without atonia postoperatively, had slight decreases in waking activity. Their lesions lay caudally and dorsally to those of the others. Cats which increased their activity did not just aimlessly pace; rather, they often ran to investigate sounds or objects they saw. The cats also were more restless when in a given square although this was not recorded quantitatively.

We conclude that the lesions disrupt a mechanism which modulates the cat's motor output, particularly when the nervous system is in a highly activated state as it is in paradoxical sleep or in wakefulness when confronted with a continuously changing environment.

We are frankly unsure at this time precisely which systems are interrupted to produce the changes in paradoxical sleep and wakefulness. Results with both waking and sleeping animals suggest that the phenomenon of paradoxical sleep without atonia depends upon destruction of a minimum of two systems and undoubtably more. Figure 6 depicts the minimum. The lesion must interrupt a pathway which either facilitates the activity of the medullary inhibitory area of the reticular formation (29) and/or directly inhibits the spinal motor neurons. The former alternative is depicted because pontine stimulation produced minimal direct effects on spinal motor neurons; whereas monosynaptic inhibition of antigravity motor neurons results from caudal medullary stimulation (47). A discrete pathway from the region of the locus coeruleus and ventromedial to it to the medulla has been described with the aid of axonal transport techniques (53). It appears to be related to the lateral tegmento-reticular tract described earlier by Russel (51). Interruption of this tract can eliminate atonia in paradoxical sleep (54). The diagram, 
however, depicts the suggestion that an additional system(s) must be involved in the release of the complex behaviors observed when the paralysis of paradoxical sleep is lifted because the increased exploratory behavior in wakefulness dictates this. Locomotor activity is basic to most of an animal's behaviors, and it is seen with the smallest lesions during

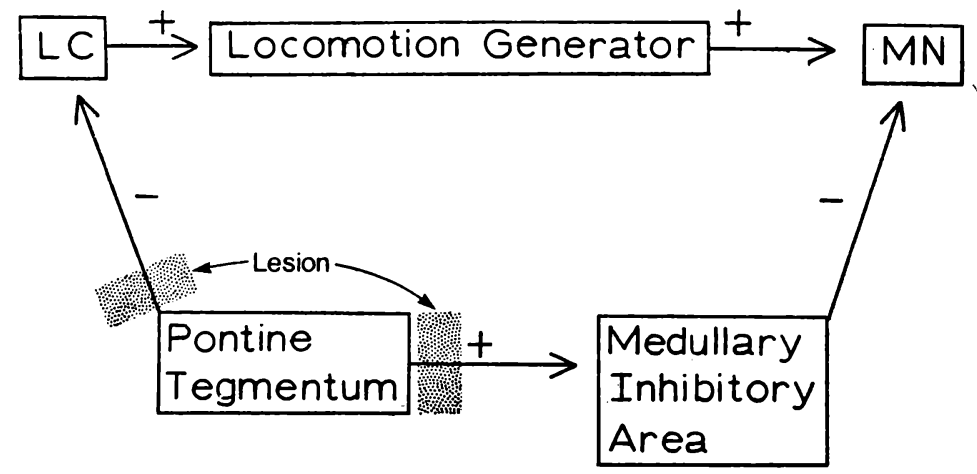

Fig. 6. Diagram of the explanation proposed for the phenomenon of paradoxical sleep without atonia. Shaded areas represent the pontine lesion which is thought to interrupt an inhibitory ( $\rightarrow$ ) influence on a brainstem locomotor center (LC) and an excitatory ( + ) influence on the medullary inhibitory area, which normally inhibits spinal motor neurons (MN). The brainstem locomotor center is believed to exert a tonic facilitatory influence on a locomotion generator, probably located in the spinal cord (55). From Morrison (33).

paradoxical sleep (Fig. 4, GM7). A large number of studies $(32,55,59)$ have demonstrated that primitive locomotion in acutely decerebrated cats can be generated by electrical stimulation of a region extending from the nucleus cuneiformis, which underlies the colliculi, through the noradrenergic neurons of the locus coeruleus into the lateral pontine tegmentum. This system may be released in paradoxical sleep and wakefulness as a result of the lesions and would be part of the primitive control mechanism set into action in exaggerated fashion by the activation of paradoxical sleep. Since decerebrate cats periodically express all of the peripheral elements of paradoxical sleep $(21,62)$, it will be important to determine whether pontine lesions in decerebrate preparations can release elementary locomotor behavior during such episodes.

More elaborate behavior, including attack, also occurs in the case of more ventrally extending lesions (Fig. 4, JH14). When intact cats are stimulated laterally to the lesion site in the region of the locomotor system they exhibit species-specific prey-killing behavior if a rat is present (2). (Interestingly, they merely locomote in the absence of a rat.) During wakefulness our lesioned cats exhibit a tendency to be aggressive toward other cats, and we are beginning to study these interactions. It 
is probable that disruption of fibers from rostral limbic areas contributes to this behavior (44).

In conclusion, the idea that paradoxical sleep is a highly activated state of the brain is not new; it was suggested by early workers (13). Our work has led us to propose further, however, that seemingly disconnected events, PGO spikes and atonia, are part of a unified mechanism, which is set in motion during the orienting state in wakefulness but which operates in exaggerated form during the special state of brain activation that is paradoxical sleep. The existence of parallel effects on motor control in wakefulness and paradoxical sleep produced by pontine lesions suggests that the atonia of paradoxical sleep is a reflection of excessive activity of a brainstem response dampening mechanism triggered by extreme reticular activation, which is signified by constant PGO spike occurrence. During wakefulness the same mechanism operates more subtly to produce appropriately modulated responses to various unexpected stimuli.

It is with great pleasure that I acknowledge the very important contributions of my colleagues, Robert Bowker, Joan Hendricks and Graziella Mann, to the work reported and to many of the ideas. Financial support was provided by National Institutes of Health grants NS-13110, NS-08377, GM-02051, MH 13767, and RR-05464, and a grant from the American Philosophical Society's Penrose Fund.

\section{REFERENCES}

1. ASERINSKY, E. and KLEITMAN, N. 1953. Regularly occurring periods of eye motility, and concomitant phenomena during sleep. Science 118: 273-274.

2. BERNTSON, G. G. 1973. Attack, grooming and threat .elicited by stimulation of the pontine tegmentum. Physiol. Behav. 11: 81-87.

3. BIZZI, E. and BROOKS, D. C. 1963. Functional connections between pontine reticular formation and lateral geniculate nucleus during deep sleep. Arch. Ital. Biol. 101: 666-680.

4. BOWKER, R. M. 1979. The biological significance of eye movement potentials of wakefulness and the PGO spikes of sleep. Unpublished $\mathrm{Ph}$. D. thesis, University of Pennsylvania.

5. BOWKER, R. M. and MORRISON, A. R. 1976. The startle reflex and PGO spikes. Brain Res. 102: 185-190.

6. BOWKER, R. M. and MORRISON, A. R. 1977. The PGO spike: An indicator of hyperalertness. In W. P. Koella and P. Levin (ed.), Sleep research-1976. Karger, Basle; p. 23-27.

7. BROOKS, D. C. 1978. Localization and characteristics of the cortical waves associated with eye movement in the cat. Exp. Neurol. 22: 603-613.

8. BROOKS, D. C. 1977. The PGO phenomenon: Inputs to the lateral geniculate nucleus from the cortex and brain stem. In W. P. Koella and P. Levin (ed.), Sleep research-1976. Karger, Basle, p. 15-18.

9. BROOKS, D. C. and BIZZI, E. 1963. Brain-stem electrical activity during deep sleep. Arch. Ital. Biol. 101: 648-665. 
10. BROOKS, D. C. and GERSHON, M. D. 1971. Eye movement potentials in the oculomotor and visual systems of the cat: A comparison of reserpineinduced waves with those present during wakefulness and rapid eye movement sleep. Brain Res. 27: 223-239.

11. CARLI, G. 1969. Dissociation of electrocortical activity and somatic reflexes during rabbit hypnosis. Arch. Ital. Biol. 107: 219-234.

12. DEMENT, W. C. 1969. The biological role of REM sleep (circa 1968). In A. Kales (ed.), Sleep: physiology and pathology. J. B. Lippincott Co., Philadelphia, p. 245-265.

13. DEMENT, W. C. 1973. Commentary on, the biological role of REM sleep (circa 1968). In W. B. Webb (ed.), Sleep: an active process. Scott, Foresman, Glenview, Ill., p. 48-58.

14. FELDMAN, M. and COHEN, B. 1968. Electrical activity in the lateral geniculate body of the alert monkey associated with eye movements, J. Neurophysiol. 31: 455-466.

15. GASSEL, M. M., MARCHIAFAVA, P. L. and POMPEIANO, O. 1965. An analysis of supraspinal influences acting on motoneurons during sleep in the unrestrained cat. Modification of the recurrent discharge of the alpha motoneurons during sleep. Arch. Ital. Biol. 103: 25-44.

16. GUILLEMINAULT, C. 1976. Cataplexy In C. Guilleminault, W. C. Dement, and P. Passouant, (ed.), Narcolepsy. Spectrum, New York, p. 125-143.

17. HENDRICKS, J. C., BOWKER, R. M. and MORRISON, A. R. 1977. Functional characteristics of cats with pontine lesions during sleep and wakefulness and their usefulness for sleep research. In W. P. Koella and P. Levin, (ed.), Sleep research-1976. Karger, Basel, p. 207-210.

18. HENLEY, K. and MORRISON, A. R. 1974. A reevaluation of the effects of lesions of the pontine tegmentum and locus coeruleus on phenomena of paradoxical sleep in the cat. Acta. Neurobiol. Exp. 34: 215-232.

19. ITO, M., YOSHIDA, M., OBATA, K., KAWI, N. and UDO, M. 1970. Inhibitory control of intracerebellar nuclei by the Purkinje cell axons. Exp. Brain Res. 10: 64-80.

20. JEANNEROD, M. and SAKAI, K. 1970. Occipital and geniculate potentials related to eye movements in the unanaesthetized cat. Brain Res. 19: 361-377.

21. JOUVET, M. 1962. Recherches sur les structures nerveuses et les mécanismes responsables des différentes phases du sommeil physiologique. Ärch. Ital. Biol. 100: 125-206.

22. JOUVET, M. 1967. Neurophysiology of the states of sleep. Physiol Rev. 47: 117177.

23. JOUVET, M. 1972. The role of monoamines and acetylcholine-containing neurons in the regulation of the sleep-waking cycle. In Ergebnisse der Physiologie: neurophysiology and neurochemistry of sleep and wakefulness. Springer-Verlag, New York, 64: 96-117.

24. JOUVET, M. and DELORME, G. 1965. Locus coeruleus et sommeil paradoxal. C. R. Soc. Biol. 159: 895-899.

25. JOUVET, M. and MICHEL, F. 1959. Corrélations électromyographique du sommeil chez le chat décortiqué et mésencephalique chronique. C. R. Soc. Biol. (Paris) 153: 422-425.

26. LAURENT, J. CESPUGLIO, R. and JOUVET, M. 1974. Délimitation des voies ascendantes de l'activité ponto-géniculo-occipitale chez le chat. Brain Res. 65: 29-52. 
27. LAURENT, J. and GUERRERO, F. A. 1975. Reversible suppression of pontogeniculo-occipital waves by localized cooling during paradoxical sleep in cats. Exp. Neurol. 49: 356-369.

28. LUND, S. and POMPEIANO, O. 1968. Monosynaptic excitation of alpha motoneurones from supraspinal structures in the cat. Acta. Physiol. Scand. 73: $1-21$.

29. MAGOUN, H. W. and RHINES, R. 1946. An inhibitory mechanism in the bulbar reticular formation. J. Neurophysiol. 9: 165-171.

30. McGINTY, D. and HARPER, R. M. 1976. Dorsal raphé neurons: depression of firing during sleep in cats. Brain Res. 101: 569-575.

31. MIKITEN, T. H., NIEBYL, P. H. and HENDLEY, C. D. 1961. EEG desynchronization during behavioral sleep associated with spike discharges from the thalamus of the cat. Fed. Proc. 20: 327.

32. MORI, S., SHIK, M. L., and YAGODNITSYN, A. S. 1977. Role of pontine tegmentum for locomotor control in mesencephalic cat. J. Neurophysiol. 40: 284-295.

33. MORRISON, A. R. 1979. Brainstem regulation of behavior during sleep and wakefulness. In J. M. Sprague and A. N. Epstein (ed.), Progress in psychobiology and physiological psychology, 8. Academic Press, New York, p. 91-131.

34. MORRISON, A. R. and BOWKER, R. M. 1973. Cerebellar and spinal contributions to the regulation of muscle tone and movement during sleep. In U. J. Jovanović (ed.), The nature of sleep. Gustav Fischer, Stuttgart, p. 270277.

35. MORRISON, A. R. and BOWKER, R. M. 1975. The biological significance of PGO spikes in the sleeping cat. Acta. Neurobiol. Exp. 35: 821-840.

36. MORRISON, A. R., HENDRICKS, J. C. and BOWKER, R. M. 1977. A new role for the locus coeruleus. Soc. Neurosci. Absts. 3: 256.

37. MORRISON, A. R., MANN, G., HENDRICKS, J, C. and STARKWEATHER, C. 1979. Release of exploratory behavior in wakefulness by pontine lesions which produce paradoxical sleep without atonia. Anat. Rec. 193: 628.

38. MORRISON, A. R. and POMPEIANO, O. 1965. An analysis of supraspinal influences acting on motoneurons during sleep in the unrestrained cat. Responses of the alpha motoneurons to direct electrical stimulation during sleep. Arch. Ital. Biol. 103: 497-516.

39. MORRISON, A. R. and POMPEIANO, O. 1966. Vestibular influences during sleep IV. Functional relations between vestibular nuclei and lateral geniculate nucleus during desynchronized sleep. Arch. Ital. Biol. 104: 425-458.

40. MORTIMER, J. 1973. Temporal sequence of cerebellar Purkinje and nuclear activity in relation to the acoustic startle response. Brain Res. 50: 457-462.

41. MORUZZI, G. 1963. Active processes in the brainstem during sleep. Harvey Lect. 58: 233-297.

42. MORUZZI, G. 1964. The historical development of the deafferentation hypothesis of sleep. Proc. Am. Philos. Soc. 108: 19-28.

43. MORUZZI, G. and MAGOUN, H. W. 1949. Brainstem reticular formation and activation of the EEG. Electroenceph. Clin. Neurophysiol. 1: 455-473.

44. NAUTA, W. J. H. 1960. Some neural pathways related to the limbic system. In E. R. Ramey and D. S. O'Doherty (ed.), Electrical studies on the unanesthetized brain. Hoeber, New York, p. 1-16.

45. PARMEGGIANI, P. L. 1977. Interaction between sleep and thermoregulation. Waking and Sleeping 1: 123-132. 
46. PELleT, J., TARDY, F., DUBROCARD, S. and HARLAY, F. 1974. Etude de l'activité électrique phasique du cortex du cervelet au cours des états de veille et de sommeil. Arch. Ital. Biol. 112: 163-195.

47. PETERSON, B. W. 1979. Reticulospinal projections to spinal motor nuclei. Ann. Rev. Physiol. 41: 127-140.

48. POMPEIANO, O. and MORRISON, A. R. 1965. Vestibular influences during sleep. I. Abolition of the rapid eye movements of desynchronized sleep following vestibular lesions. Arch. Ital. Biol. 103: 569-595.

49. POMPEIANO, O. and SWETT, J. E. 1962. EEG and behavioral manifestations of sleep induced by cutaneous nerve stimulation in normal cats. Arch. Ital. Biol. 100: 311-342.

50. RATNER, S. C. 1967. Comparative aspects of hypnosis. In Handbook of clinical and experimental hypnosis, J. E. Gorden (ed.), MacMillan, New York, p. 550587.

51. RUSSEL, G. V. 1955. The nucleus locus coeruleus (dorsolateralis tegmenti). Tex. Rep. Biol. Med. 13: 939-988.

52. SAKAI, K. and CESPUGLIO, R. 1976. Evidence for the presence of eye movement potentials during paradoxical sleep in cats. Electroencephalogr. Clin. Neurophysiol. $41: 37-48$.

53. SAKAI, K., SASTRE, J. P., SALVERT, D., TOURET, M., TOHYAMA, M. and JOUVET, M. 1978. Tegmento-reticular projections responsible for muscle atonia during paradoxical sleep in the cat. Sleep Res. 7: 42.

54. SASTRE, J. P., SAKAI, K. and JOUVET, M. 1978. Bilateral lesions of the dorso-lateral pontine tegmentum. II - Effect upon muscle atonia. Sleep Res. 7: 44.

55. SHIK, M. L. and ORLOVSKY, G. N. 1976. Neurophysiology of locomotor automatism. Physiol. Rev. 56: 465-501.

56. SIMON, R. P., GERSHON, M. D. and BROOKS, D. C. 1973. The role of raphé nuclei in the regulation of ponto-geniculo-occipital wave activity. Brain Res. 58: $313-330$.

57. SINGER, W. 1977. Control of thalamic transmission by corticofugal and ascending reticular pathways in the visual system. Physiol. Rev. 57: 386-420.

58. SOKOLOV, E. N. 1963. Higher nervous functions: The orienting reflex. Ann. Rev. Physiol. 25: 545-580.

59. STEEVES, J. D., JORDAN, L. M. and LAKE, N. 1975. The close proximity of catecholamine-containing cells to the mesencephalic locomotor region (MLR). Brain Res. 100: 663-670.

60. STERIADE, M. and HOBSON, J. A. 1976. Neuronal activity during the sleepwaking cycle. Prog. in Neurobiol. 6 : 155-376.

61. TRULSON, M. E. and JACOBS, B. L. 1978. Raphé unit activity in freely moving cats: correlation with level of behavioral arousal. Brain Res. 163: 135150.

62. VILLABLANCA, J. 1966 Behavioral and polygraphic study of "sleep" and "wakefulness" in chronic decerebrate cats. Electroencephalogr. Clin. Neurophysiol. 21: 562-577.

63. YU, J., TARNECKI, R., CHAMBERS, W. W., LIU, C. N. and KONORSKI, J. 1973. Mechanisms mediating ipsilateral limb hyperflexion after cerebellar paravermal cortical ablation or cooling. Exp. Neurol. 38: 144-156. 